\title{
Data Processing as a Source of Psychological Researches Results' Ambiguity
}

\author{
Elena. V. Belovol \\ PhD, associate professor, Social and Differential Psychology Chair, \\ Peoples' Friendship University of Russia, Moscow, \\ belovol@mail.ru
}

\author{
Doi:10.5901/ajis.2013.v2n9p340
}

\begin{abstract}
By the example of empirical research and analysis of correlations between person's cognitive styles and his/her personal characteristics it is shown that contradictions and ambiguity of presented in psychological literature data on the topic are due to inadequate mathematical methods of data processing.
\end{abstract}

Keywords: cognitive style, field dependence - field independence, constricted-flexible control, breadth of categorizing, impulsivity reflectivity, correlation analysis, factor analysis, regression analysis, cluster analysis.

\section{Introduction}

Practically every scientist reading special literature eventually runs into contradictions in the results presented by different authors. Every time facing this problem researcher has to decide whether to accept presented results or no. For example, in the researches devoted to revealing of relationship between hemispheric asymmetry and cognitive style field dependence - field independence (FD-FID) some authors find this correlation (Silverman et al., 1966, Pizzamiglio, 1974, Witkin et al., 1977). At the same time, some authors do not (Zhumgalieva, 2002, Gasimov, 1997). 1480 participants took part in B.K. Zhumgalieva's research and she wrote "...no correlation was found between type of hemispheric asymmetry and cognitive style FD-FID". About contradictoriness of data wrote a great number of authors all around the world.

Every time facing such problem researcher has to decide whether to accept presented results or no. If the answer is "yes" - then a scientist's next step is to decide what results he/she should accept. In case of "no" - answer a scientist sometimes forced to duplicate the study spending time and money. Such circumstances resulted in different inconsistent psychological theories, theirs diversity impede understanding reality. There are a great number of reasons for such diversity, but in the study only one aspect of the problem was examined - the problem of data processing.

Unfortunately, it should be acknowledged that sometimes researchers forget the warning of Russian scientist A. Krylov: "Mathematics is like millstones; they mill only what is put into them. If seeds of weed are put into - it is impossible to expect that one would obtain wheat flour". Lack of understanding about data processing essence is unacceptable, dangerous and results in ambiguous conclusions.

One should acknowledge that very often the set of actions which some authors called "processing and analysis of psychological researchers' data" is not always understand as a kind of specific process which can't be reduced to a number of mathematical methods. Lack in understanding of the process results in ineffective application of mathematical instrument and more over to conclusions that sometimes don't correspond to the reality and even sometimes contradict it.

In our research by the example of empirical research and analysis of correlations between person's cognitive styles and his/her personal characteristics it is shown that contradictions and ambiguity of presented in psychological literature data on the topic are due to inadequate mathematical methods of data processing.

Term cognitive style refers to an individual's way of processing information. May be the most popular definition for cognitive styles was given by American psychologist Samuel Messick. Cognitive styles according to his definition are characteristic modes of perceiving, remembering, thinking, problem solving and decision making. They are inferred from consistent individual differences in ways of organizing and processing information and experience.

The problem of place and role of cognitive styles in the structure of personality has been a continuous issue for more than seventy years, since 1950-s of the past century. However, the researches in the field do not avoid typical for a number of psychological researches contradictions.

Sometimes it is the result of mistake in method of data analysis. For example, recalculation of H.A.Witkin's results on gender differences in ease of perception of embedded figures (Witkin, 1950) does not confirm his conclusion. To 
reveal these differences the author used $t$-test to compare the means of the two samples. However, as we know now this test can be used only in case of variables' normal distribution. Recovery of given in the paper data showed that their distributions are far from normal (fig.1).

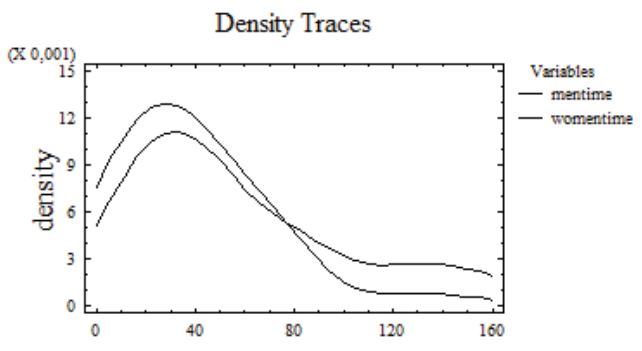

Fig. 1. Density traces for indices of time in Embedded Figures Test (recovered from Witkin, 1950)

As we know for distributions of this type adequate measure of central tendency is median and not mean which is used for t-test. So, if "right" test is used, it can be, for example, Mann-Whitney $W$ test to compare the medians of the two samples, the results will be quite different. The value of $W$ test and its level of significance $(W=361,0 p=0,135)$ proved the absence of difference between variables at the $95,0 \%$ confidence level. Thus the application of another corresponding to data type mathematical method gives another results, another interpretation and of course another theory.

Not only comparative analysis can be the source of discrepancies in the results but methods of interrelation study as well. Thus in different researches conducted by different authors at different periods one can find different correlations as in values and in their number between cognitive styles and personal characteristics (Cooper, Lyne, 1977, Holodnaya, 2004, Libin, 1999, etc.). The fact enables M. Holodnaya to state "correlations between separate cognitive styles and different personal features are characterized by diversity and contradictions" (Holodnaya, 2004, p. 277).

Correlation analysis of examined variables from the very beginning revealed contradictory results. Thus, the use of different correlation coefficients results in different conclusions. There are a number of different coefficients. Among them are historically first Pearson's coefficient of correlation, rank coefficient or Spearman's correlation and one of the latest Kendall's coefficient of correlation.

By the example of correlation between person's cognitive styles and personal characteristics measured by means of Kettell's questionnaire (16-PF) complicacy and pitfalls at this stage of analysis of data connected with the study of interrelations between variables is demonstrated.

\section{Method}

Data for the study was received in the result of special study. 67 participants, with average age of 19, 7, students of different Moscow universities took part in the research.. Four cognitive styles: field dependence - field independence, constricted-flexible control, breadth of categorizing, impulsivity - reflectivity were examined by means of a standard procedure (Jonanssen, Grabowski, 1993). Personal characteristics as it was mentioned above were examined by means of Kettell's 16-PF.

\section{Results}

The first step in the study of interrelations between variables is correlation analysis. In figure 2 correlations between one of the cognitive styles notably constricted-flexible control and personal characteristics are presented schematically. They were obtained with the help of different correlation coefficients. Cognitive style constricted-flexible control is defined as one's readiness (or lack thereof) to review and change one's judgment of a proposed solution to a problem. Color-Word Test (Stroop, 1935; Golden, 1978) is used for this cognitive style measuring and consists of the words in part 1, printed in the colors of part 2 and of items written as XXXX printed in either red, green, or blue ink which are to be named by color (part 3). The task is to name the color of the ink that the words are printed in rather than reading the color words themselves. The automatic word-reading response must be suppressed through volitional control. (Index Stroop_D in the 
figure corresponds to difference in time of performance part 2 and part $3\left(T_{3}-T_{2}\right)$ of the test, and index Stroop_T corresponds to $T_{2} / T_{1}$ ratio.)

Spearman coefficient

Fig.2. Correlations between cognitive style constricted-flexible control and Kettell's personal characteristics (numbers in the figure corresponds to correlation's level of significance)

From correlation diagrams (usually they are named graphs and theirs representations follow certain rules, but in our case they are simplified) we can see that the results of correlation analysis are different for different correlation coefficients. The number of significant correlations (from 1 to 3 ) and variables themselves (between Stroop_D and C, H, Q 4 when Spearman correlation was used, between Stroop_D and C, H, as well as Stroop_T and C - when T-Kendall was calculated and between Stroop T and M in case of Pearson correlation) are very different. Thus the results of correlation analysis rather puzzle and produce certain problems for factful interpretation of the obtained data. One should not forget that correlation is only statistical relation between variables and sometime we can find it between foot size and problem solving rate!

Eighteen different variables are used in our study. Such number makes it possible for us to remember about multidimensional methods of data processing and about factor analysis in the first place. Its results are presented bellow in table 1. Usually factor analysis begins with factors' number determination. This procedure is realized after eigenvalues' and percent of variance per factor determination. Of course, it is an ideal situation when many variables are described by a few factors that describe $100 \%$ of variance. However, it's is a rare case. In psychological studies there is a tradition to define a number of factors either by a minimum eigenvalue either by part of variance explaining a number of factors (60\% is considered sufficient enough in psychological studies). In our case if we use a rule of "eigenvalue less than one" we can chose 6 -factors solution, and 4-factor solution if we use a "rule of variance". Eigenvalues are presented in table 1 that is the basis for decision-making.

Table 1. Eigenvalues

\begin{tabular}{|c|c|c|c|c||}
\hline Variable & Eigenvalue & \% Total variance & Cumulative Eigenvalue & Cumulative \% \\
\hline \hline 1 & 4,756440 & 26,42467 & 4,75644 & 26,4247 \\
\hline
\end{tabular}




\begin{tabular}{|c|c|c|c|c|}
\hline 2 & 3,414501 & 18,96945 & 8,17094 & 45,3941 \\
\hline 3 & 2,015398 & 11,19666 & 10,18634 & 56,5908 \\
\hline 4 & 1,905954 & 10,58863 & 12,09229 & 67,1794 \\
\hline 5 & 1,224598 & 6,80332 & 13,31689 & 73,9827 \\
\hline 6 & 1,053076 & 5,85042 & 14,36997 & 79,8331 \\
\hline 7 & 0,708088 & 3,93382 & 15,07806 & 83,7670 \\
\hline 8 & 0,686880 & 3,81600 & 15,76494 & 87,5830 \\
\hline 9 & 0,603246 & 3,35136 & 16,36818 & 90,9343 \\
\hline 10 & 0,440491 & 2,44717 & 16,80867 & 93,3815 \\
\hline 11 & 0,402858 & 2,23810 & 17,21153 & 95,6196 \\
\hline 12 & 0,321027 & 1,78348 & 17,53256 & 97,4031 \\
\hline 13 & 0,194400 & 1,08000 & 17,72696 & 98,4831 \\
\hline 14 & 0,143615 & 0,79786 & 17,87057 & 99,2810 \\
\hline 15 & 0,081454 & 0,45252 & 17,95203 & 99,7335 \\
\hline 16 & 0,037237 & 0,20687 & 17,98926 & 99,9403 \\
\hline 17 & 0,007364 & 0,04091 & 17,99663 & 99,9813 \\
\hline 18 & 0,003374 & 0,01874 & 18,00000 & 100,0000 \\
\hline
\end{tabular}

In our case according to "eigenvalue less than one" rule we have chosen six-factor solution. This decision are presented in the table of factor loadings (table 2).

Table 2. Factor loadings

\begin{tabular}{|c|c|c|c|c|c|c|}
\hline variable & Factor 1 & Factor 2 & Factor 3 & Factor 4 & Factor 5 & Factor 6 \\
\hline A & $|-0,189547|$ & $-0,092735$ & $-0,042774$ & $0,845126^{*}$ & $-0,141863$ & 0,120580 \\
\hline B & 0,668001 & $-0,092108$ & $-0,181502$ & $-0,065840$ & 0,375471 & 0,039720 \\
\hline C & 0,037880 & $-0,822238$ & 0,202843 & 0,025343 & 0,236866 & 0,229555 \\
\hline$E$ & 0,884598 & 0,019721 & 0,037690 & $-0,086124$ & 0,044258 & 0,303139 \\
\hline$F$ & 0,790848 & 0,211222 & 0,333253 & 0,106124 & $-0,155588$ & $-0,056163$ \\
\hline $\mathbf{G}$ & $-0,068981$ & 0,053497 & $-0,895276$ & 0,148114 & $-0,061161$ & $-0,122280$ \\
\hline $\mathrm{H}$ & 0,842842 & 0,011970 & $-0,044278$ & 0,107062 & 0,315952 & 0,175143 \\
\hline $\mathrm{I}$ & 0,410326 & 0,043934 & $-0,010855$ & $-0,076214$ & 0,606425 & $-0,245289$ \\
\hline L & 0,085655 & 0,598218 & 0,258646 & 0,295509 & 0,212818 & 0,473656 \\
\hline$M$ & 0,462512 & 0,120331 & 0,201706 & 0,041497 & 0,129257 & 0,700097 \\
\hline $\mathrm{N}$ & $-0,269580$ & 0,200322 & $-0,075799$ & 0,322926 & $-0,004648$ & $-0,772899$ \\
\hline 0 & $-0,023987$ & 0,883699 & 0,189960 & 0,108386 & $-0,056861$ & $-0,069984$ \\
\hline Q_1 & 0,632832 & $-0,156038$ & $-0,334597$ & 0,033655 & 0,044586 & 0,508280 \\
\hline Q_2 & $-0,294015$ & $-0,043927$ & 0,029646 & $-0,831336$ & $-0,214166$ & 0,247460 \\
\hline Q_3 & 0,047234 & $-0,415191$ & $-0,763934$ & $-0,124907$ & 0,100466 & $-0,067284$ \\
\hline Q_4 & 0,129938 & 0,883554 & 0,106649 & $-0,206308$ & $-0,055974$ & 0,058117 \\
\hline Stroop_T & 0,034289 & $-0,095155$ & 0,324346 & 0,292923 & 0,555432 & 0,510318 \\
\hline Stroop_D & $-0,124357$ & 0,260732 & 0,059691 & $-0,027828$ & $-0,810904$ & $-0,162197$ \\
\hline
\end{tabular}


Analysis of loadings prevent us from expecting interrelations between personal characteristics and cognitive style constricted -flexible control. Factor 5 includes cognitive style index but none of personal characteristics load this factor!!! According to factor analysis methodology this fact indicates the fact of independence of variables under study. In principle, we can be satisfied with this result, but some contradictions between the results of correlation and factor analyses requires to find out the solution of the problem.

As an example let's consider liner regression equation for variable responsible for the effect of interference (Stroop_D) in cognitive style and Kettell's C factor characterizing emotional stability. Note that we use these variables because correlation analysis reveals uncertain interrelation The following equation was obtained:

$C=19,978-0,10111$ Stroop_D

The line is presented in fig. 3

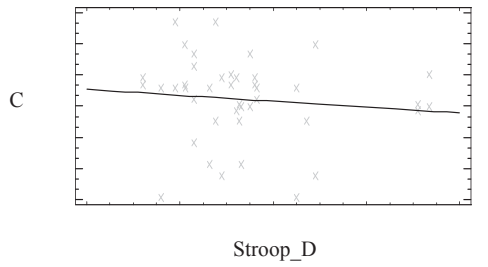

Fig. 3. Plot of fitted model

Since the P-value in the ANOVA analysis is less than 0,05 , there is no statistically significant relationship between variables under study at the $95,0 \%$ confidence level. The R-Squared statistic indicates that the model as fitted explains $15,6629 \%$ of the variability. The results are obviously insufficient to decide for existence of interrelation between variables.

Therefore, in spite of the fact that correlation analysis reveals certain unstable correlations, the other mathematical methods of interrelations study (factor and regression analyses) don't confirm the results of correlation analysis. Therefore, the results of conducted analysis enable to state the absence of regular interrelation between variables describing person's individual features and his/her cognitive style constricted-flexible control. More over these results are confirmed by cluster analysis.

Cluster analysis is an exploratory data analysis tool for solving classification problems. Its object is to sort variables (cases, people, things, events, etc) into groups, or clusters, so that the degree of association is strong between members of the same cluster and weak between members of different clusters.

The results of cluster analysis are presented in fig. 4.

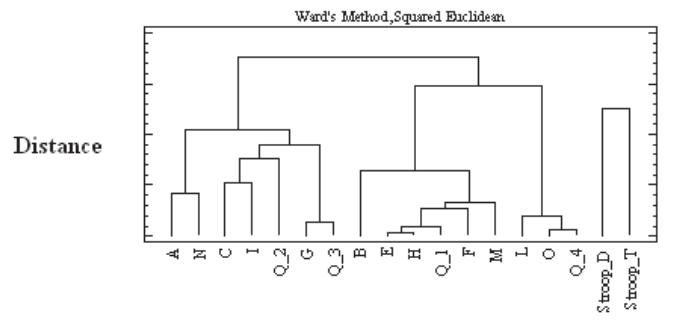

Fig. 4. Dendrogram 1.

From dendrogram in fig. 3 is obviously that variables connected with cognitive style constricted-flexible control form independent group apart from variables which are connected with personal characteristics.

The conclusion drawn out from the results of factor and regression analyses are the same. Therefore, we can be sure there is no interrelation between these groups of variables.

As for another cognitive styles observed in the study the same multistep analysis have been conducted. Its results bring us to the conclusion that variables connected with cognitive styles field dependence - field independence, constricted-flexible control, breadth of categorizing, impulsivity - reflectivity and characteristics at personal level are not 
connected with each other. They are autonomous characteristics of personal characteristics at different levels of personality. Fig. 5 confirms this result.

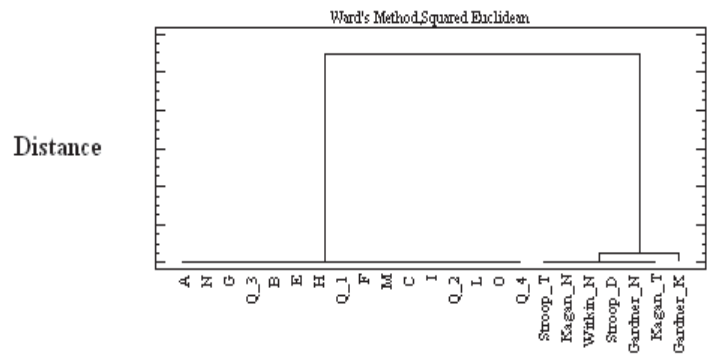

Fig. 5. Dendrogram 2.

Thus conducted research makes it possible to remove uncertainty connected with the identifying of cognitive styles' role of in the structure of personality and to confirm the validity of functional model of cognitive styles (Belovol, 2013). According to this model cognitive styles can be considered as "instruments" of mental image forming, that realize the main function of psyche - the reflective one. This function is "...not in the process of activation on its own and nor in generation, nor in conducting and integration of nerve impulses but in the construction of the image of the world, construction of nerve models of the world that surrounds human been" (Tchupricova, 2005).

\section{Summary}

1. Analysis of psychological literature reveals a number of contradictions and inconsistencies in the results of cognitive styles studies. It has been shown that sometimes it is the result of inadequate mathematical methods of data processing.

2. Empirical study of interrelations between cognitive styles and personal characteristics has been conducted.

3. By the example of analysis of interrelations between constricted-flexible cognitive style and Kettell's personal characteristics the ambiguous results of data analysis are shown to be the result of different methods' application.

4. To avoid such ambiguity one should keep in mind specific character and range of application of different methods of data processing.

\section{References}

Belovol E.V. The image of the "other": cognitive style approach//Humanities and Social Sciences Rewiev.CD-ROM.ISSN:21656258:2(1):207-213 (2013), pp.207-213.

Jonanssen D.H., Grabowsru B.L. Handbook of individual differences, learning and instruction. Hillside NJ, 1993

Pizzamiglio L. Handedness, ear-preference and field dependence. Perceptual and Motor Skills, 1974, 38, pp. 700-702.

Silverman A.J., Anevai G, McGough W.E Some relationships between handedness and perception // Journal of Psyhosomatic Research, $1966,10,151-158$.

Witkin H.A. Individual differences in ease of perception of embedded figures"// J. Of Personality, 1950, v.19, pp.1-15.

Witkin H.A., Moore C.A., Goodenough D.R., Cox P.W. Field-dependent and field-independent cognitive styles and their educational implications// Review of Educational Research, 1977, v.47, pp. 1-64

Gasimov F.M. To the problem of correlation between cognitive style and hemispheric brain asymmetry/l Actual problems of psychophysiology and neuropsychology. - M., 1991.- pp. 233-241.

Zhumgalieva B.K. Ethnocultural peculiarities of cognitive style and picture of the world in persons with different hemispheric asymmetry: author's abstract of PhD dissertation. - M., 2002.

Libin A.V. Differential psychology: at the cross-road of European, Russian and American traditions. - M.: Smysl, 1999,- 532 p.

Holodnaya M.A. Cognitive styles: on the nature of individual mind. - St. Petersburg.: Piter, 2004. - 384 p.

Tchupricova N.I. Object, subject and methods of psychological science// Proceedings of Yaroslavl methodological seminar. Vol.4. Yaroslavl, 2005. - pp. 359-369. 